\title{
Measles outbreaks in pakistan: causes of the tragedy and future implications
}

\author{
Tariq Khan and Javaria Qazi* \\ *Correspondence: javariaq@yahoo.com

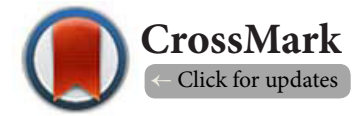 \\ Department of Biotechnology, Quaid-i-Azam University, Islamabad-45320, Pakistan.
}

\begin{abstract}
Measles outbreaks have been reported in various parts of the world; however, they have not claimed as many lives as in Pakistan (2012-2013). These outbreaks started in December 2012 in Sindh Province and spread afterwards to the north of country (Punjab province). The outbreaks claimed about 321 lives in the year 2013. This article gives an overview of this epidemic, highlights possible causes and presents suggestions for future implications. This review suggests that the outbreaks mainly stemmed from corruption in the health sector which resulted in an ineffective health care system, shortage of vaccinators and low immunization coverage. Poor disaster management and subsequent widespread malnutrition in children living in the flood affected areas of Sindh, contributed to the transition of local Measles outbreaks into a wide spread epidemic in the country.
\end{abstract}

Keywords: Measles, immunization, health, Pakistan, outbreaks, vaccination

\section{Introduction}

Measles is a highly contagious viral disease, of the respiratory tract which is manifested as fever, cough, and rashes all over the body. Vaccine is so far the best antidote employed to immunize the world against this child-killer [1]. After the intensive vaccination programs, all over the world, $71 \%$ drop occurred in deaths due to measles between 2000 and 2011, with reduced mortality i.e., 1 out of $1,000[2,3]$. However, despite such success, the virus continues to cause chaos in the form of outbreaks in different parts of the world $[4,5]$.

Pakistan, one of the developing countries, has lost hundreds of lives to measles as a result of last year's outbreaks in many different areas [6]. It is most unfortunate that despite the WHO's new Global Measles \& Rubella Strategic Plan 2012-2020 [7], Pakistan has still reported such a high number of outbreaks (281) and deaths due to measles. The outbreaks started in the Sindh province of Pakistan in December, 2012 and killed as many as 321 children till august, 2013. The decline of outbreaks started after August, 2013 and no prominent figures of deaths due to measles are noted. The situation became more serious when the outbreaks started in other provinces especially Punjab, which is the most densely populated province of Pakistan. Unfortunately, in the first half of 2013, 94 souls became victim to Measles in Punjab province as compared to the 16 deaths in 2012 in this area. It is alarming that a majority of these deaths occurred not in the under developed rural areas but in the capital city of the Province i.e., Lahore [8].

Unfortunately, in this age of medical science and technology, children in Pakistan are still fighting for their lives against vaccine preventable diseases. This article hereby reports the possible causes of the measles epidemic in the country with focus to the future implications and strategies for preventing such tragedies.

\section{Review}

\section{Immunization in pakistan: a brief insight}

Immunization in Pakistan has always been underachieved. Data from the WHO suggests that average routine immunization coverage was $68 \%$ in 2010 with $86 \%$ in Punjab, $74 \%$ in Khyber Pakhtunkhwa, $68 \%$ in Sindh and a very low percentage of $43 \%$ was reported from Balochistan. The total coverage figure increased up to $75 \%$ in 2011 . But, only routine immunization activities are not sufficient to fight against vaccine preventable diseases. Therefore, the routine immunization activities are supplemented with pulse doses in Pakistan. Talking about vaccination with Measles containing vaccine (MCV), the coverage figures kept on increasing since the last three decades with the highest of $88 \%$ coverage in 2012 [9]. But the situation is still gloomy, because coverage with the second dose (MCV2) is still only $53 \%$ which is not sufficient to prevent outbreaks as recommended by the WHO $[1,9]$.

\section{Measles: statistics from pakistan}

The outbreaks started in Sindh province of the country in December 2012 and spread into many other parts of the country claiming further lives $[10,11]$. Going back into the recent years, analysis suggests that Pakistan has seen a remarkable surge in deaths as well as number of measles cases in the recent years. As compared to the 64 deaths in 2011, 310 deaths have been reported in 2012 [12]. In 2013, the situation got very serious as many as 321 children and adults including those from Sindh and now Punjab, Balochistan and Khyber Pakhtunkhwa became 
victim to measles. As shown in the map in Figure 1, Sindh was the hub of victims, reporting about 150 deaths in the first half of the year 2013, while, Punjab was at the second place with respect to deaths due to measles [8].

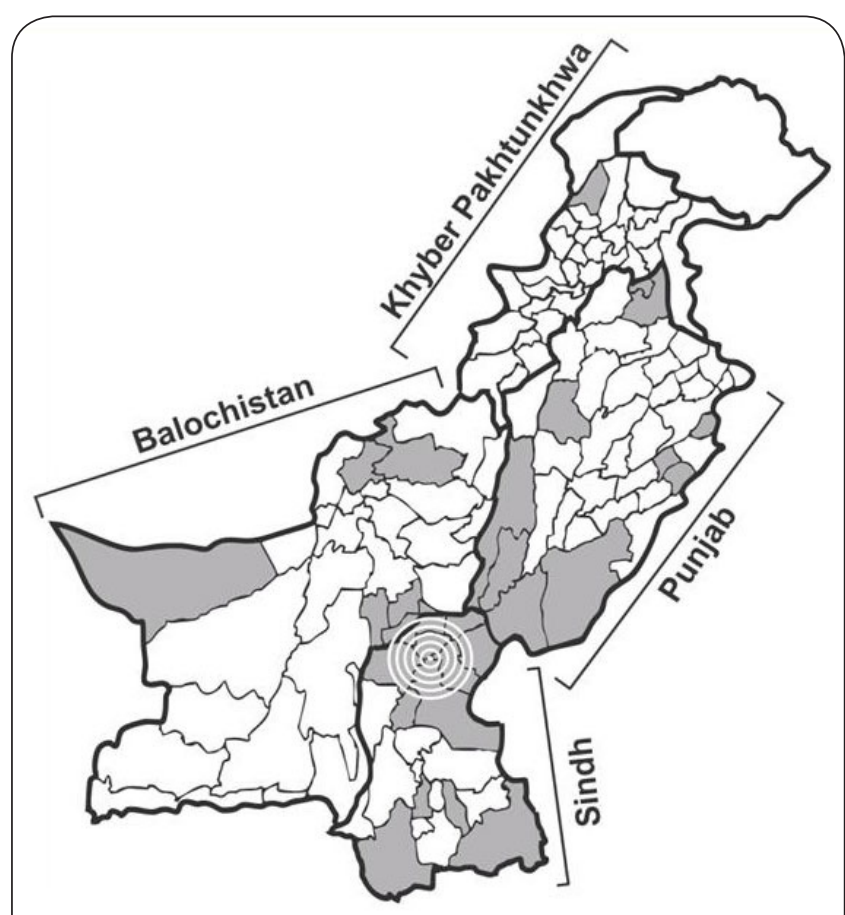

Figure 1. Province-wide distribution of Measles cases during the outbreaks in Pakistan (2013).

Talking about the lab confirmed cases during the outbreaks in Pakistan, 5969 cases were reported as compared to the 2676 confirmed cases in 2012, which unfortunately made Pakistan the highest measles reporting country in the Eastern Mediterranean region in 2013 [2,13]. Furthermore, the official data of 2013 in the weekly epidemiological bulletin reported a staggering 16, 000 suspected cases of measles in the first half of 2013. Comparison of data of cases from 2012 and 2013 suggests an interesting behavior in different provinces and regions. After the outbreaks started in Sindh, Punjab became the playground for the virus with the suspected cases reaching a remarkable 8341 in 2013, as compared to just 1329 in 2012 [8].

\section{What caused the lapse?}

There is an unending tug of fights between viruses and communities in developing countries. Outbreaks of measles were and are happening in different parts of the world but such number of cases and deaths in a short span of time indicates that there are some serious gaps that needs to be bridged $[4,5,14,15]$. As the outbreaks continue in different parts of the country $[10,11,16,17]$, the most important thing is that the number of measles cases and deaths reported so far from the country are mainly from Sindh and Punjab provinces as illustrated in Figure 1 [18]. While trying to answer the basic question that why a high number of deaths every time the virus hits the country, the following causes were identified.

\section{Corruption in health system}

Corruption, as a result of mismanagement is prevailing in poor and less developed countries (LDCs) of the world. Pakistan is ranked as one of the leading country in corruption by the Transparency International, having a very low score only 27 on the corruption perceptions index in 2012 [19]. Health care has always been a victim to corruption in Pakistan $[12,20,21]$. According to a report by the Transparency international, health is one of the leading corrupt sectors in Sindh where Measles outbreaks initiated [22]. Corruption in Pakistan ranges from government and regulatory level to the service delivery and public-private interface level. It includes illegal funds allocation, illegitimate drug pricing and marketing, staff absenteeism, under the table payments, behavior of health care providers, quackery and lack of institutional mechanism for regulation of health activities [23]. These breaches in the health department has resulted in weakening the already shaken foundations of the health infrastructure of this country.

\section{Poor health infrastructure}

The lack of basic health facilities and the government's failure to provide a strong institutional framework for health is observed as the main cause of misery. All these failures due to weaknesses like corruption are depicted in a national report by the UNICEF. The low child well-being index in Sindh and thus the higher percentage (68\%) of deprived districts in this province is a clear indicator of this major health breach. Furthermore, analysis suggested that outbreaks of measles in Sindh started in the less developed districts like Mirpurkhas, Thatta, Jacobabad and Tharparkar [24]. The implications of this poor health infrastructure are far reaching and these dents in the basic health care system have resulted in a weaker system of immunization in the country.

\section{Lower immunization coverage}

The substandard performance of expanded program on immunization (EPI) in Pakistan has resulted in failure against vaccine preventable diseases including Measles and Polio $[12,25]$. The WHO recommends two doses of measles vaccines and vaccination coverage up to or above $95 \%$ with both doses for interrupting endemic transmission of measles in many countries [26]. But, the situation is worrisome in Pakistan where the official estimate reported $75 \%$ and $53 \%$ coverage in 2011 and $80 \%$ and $53 \%$ in 2012 with the $1^{\text {st }}$ and $2^{\text {nd }}$ dose, respectively [27]. It has been reported that Pakistan is one of the five countries where 10 million children did not receive vaccination against Measles in 2011, the outcome of which can be seen in the form of these outbreaks [28].

Low immunization coverage as a result of workload on 
vaccinators, lesser awareness, socio-economic status, and distance to facility has now become one of the forefront problems of Pakistani health care system [29]. The already debilitated public health system was further compromised by the low level of vaccination coverage. There is more than one cause of the low level of coverage in Pakistan.

\section{Destabilized routine immunization}

Undermining routine immunization of measles and other vaccine preventable diseases is considered as the reason for the low level of vaccination coverage. Routine immunization has not been given that much importance which it deserves. Looking from another angle, one assumption is that people are confused by the difference in vaccination strategies against vaccine preventable diseases. Though all such diseases need intense immunization, yet against some diseases like polio, door to door immunization is performed, while people are expected to bring their children to vaccination camps to get vaccinated against the others like measles [12].

\section{Negligence among Parents}

Negligence among parents is also one of the main reasons of lower vaccination coverage among children vaccinated [30]. This negligence on part of the parents is in turn due to many reasons like lesser awareness about the importance of vaccination, and inaccessibility to the vaccination centers [31]. Another worrisome situation arose when parents from some religious communities in Sindh refused to vaccinate their children stating that it is no disease and is a test of faith as some goddess has entered the children and will abstain after sometime [32].

\section{Shortage in number of vaccinators}

Another contributing factor to improper vaccination and in turn outbreaks has been identified as the low number of vaccinators across the country. Although the low number has no direct link to the outbreaks, yet as suggested by the EPI's report, the number of vaccinators that need to be increased, has unfortunately reduced to half its number per specific area [33]. More worrying situation prevails when workers do not go for outreach vaccination programs, which has resulted in low level of immunization and thus the epidemic [31].

\section{Impact of floods}

Floods are the natural disasters which have hit the areas of Sindh over the past three consecutive years. Floods had either a direct or indirect impact not only on measles vaccination but other vaccination campaigns also in this area including polio [34]. Measles can cause deadly outbreaks in countries experiencing or recovering from a natural disaster or conflict [1]. The direct impact of floods include compromising the cold chain necessary for vaccines and thus the quality of vaccines [31], and paralysis of already weak health infrastructure and health services that in turn interrupts routine immunization
[1]. Other serious impacts are overcrowding in residential camps that greatly increases the risk of infection, and pressure on food stocks causing malnutrition, disturbed water supply and compromised hygiene $[1,35,36]$.

\section{Malnutrition}

Malnutrition, which is an important risk factor, has been identified as an important cause of such a high vulnerability to the disease in Sindh [12]. According to the National Nutrition Survey of Pakistan (2011), Sindh was determined as the poorest and most food deprived province of the country with only 28.2 per cent households having food security, while the remaining (about 72 per cent) was found to be food insecure. When this is compared to $58 \%$ of households with food insecurity at national level, situation in Sindh is alarming [37]. In an area that already had high rates of malnutrition, the floods have resulted in a serious situation [35]. All these causes are related in one way or the other. The relationship between them is represented by the schematic representation in Figure $\mathbf{2}$. Pakistan, needs to address these issues systematically to avoid such outbreaks in the future. Looking at the causes, the following recommendations can be stated.

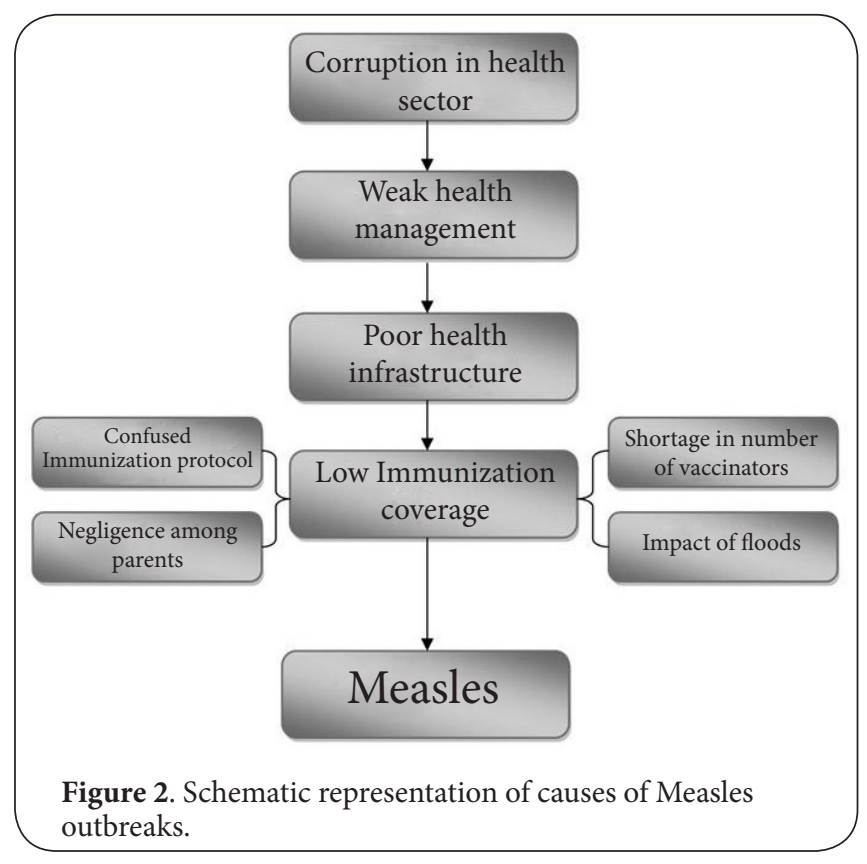

Recommendations and future implications

Although there is a lot of literature published on the breaches and suggestions to improve health infrastructure of Pakistan $[12,25,38-40]$, yet no significant measures have been taken so far to mend them. The need of the hour is to get out of the paperwork, reports and surveys, and put some practical strategies right away to implement the basic reforms already suggested by many analytical and systematic reviews $[21,40]$. 
Khan et al. Epidemiology Reports 2014,

http://www.hoajonline.com/journals/pdf/2054-9911-2-1.pdf

doi: 10.7243/2054-9911-2-1

Moreover, there is a dire need for new health facilities at government level at least for primary care in rural and urban Sindh and smooth running of the existing facilities. These basic facilities can then provide the basis and the opportunity for potential integration and coordination of services including routine immunization.

As obvious from points discussed earlier this worst situation has developed mainly due to administrative problems. Thinking along these lines it is suggested that main step towards the improvement of situation must be taken by the government. More or less, efforts for vaccination are attributed to WHO and sister organizations. But, root causes are to be addressed by the government itself such as poor sanitation and water problems. Unfortunately, these basic things have not been improved since long and this ignorance has resulted in deaths of little souls. Vaccination outreach programs should be designed to reach to the neglected children in the far-flung areas of the country.

Pakistan needs the world's focus as the reservoir of such viruses can be a risk to other measles free countries via migrations [41]. Collective efforts are required from the federal and provincial governments in Pakistan, donor agencies and the civil society. Most important step in this regard is the strengthening of the routine immunization system in Pakistan on a sustainable basis. This system will not only help in the eradication of measles but also other vaccine preventable diseases like polio from the country. Both federal and provincial governments need to allocate funds to strengthen the immunization system in the country. The routine program needs up gradation to include previously uncovered areas. As the low number of vaccinations is a big hurdle in the way of a successful eradication campaign, it needs to be substantially increased. Apart from these long term measures to cope with the recent outbreak of measles, government and the donor agencies should immediately take some steps, like a highquality widespread vaccination campaign against Measles and guaranteeing the availability of vaccines. The government should launch awareness raising campaigns to highlight the importance of routine immunization and specifically the measles in this case. Furthermore, food shortage should be given serious attention. The critical malnutrition situation needs immediate attention by the officials. An integrated effort involving multiple sectors, departments and organizations is required to improve the situation.

\section{Conclusions}

Summing up, in underdeveloped countries like Pakistan, Measles along with other vaccine preventable diseases are causing life threatening outbreaks due to lesser attention, mismanagement, corruption, weak immunization and poor response to the natural disasters.

\section{Competing interests}

The authors declare that they have no competing interests.

Authors' contributions
\begin{tabular}{|l|c|c|}
\hline Authors' contributions & TK & JQ \\
\hline Research concept and design & -- & $\checkmark$ \\
\hline Collection and/or assembly of data & $\checkmark$ & $\checkmark$ \\
\hline Data analysis and interpretation & $\checkmark$ & -- \\
\hline Writing the article & $\checkmark$ & $\checkmark$ \\
\hline Critical revision of the article & $\checkmark$ & $\checkmark$ \\
\hline Final approval of article & -- & $\checkmark$ \\
\hline Statistical analysis & $\checkmark$ & -- \\
\hline
\end{tabular}

\section{Acknowledgement}

Higher Education Commission, Pakistan and the Department of Biotechnology, Quaid-i-Azam University, Islamabad for providing support and facilities.

\section{Publication history}

Editors: Randall E. Harris, The Ohio State University, USA. Nicola Luigi Bagazzi, University of Genoa, Italy. Received: 16-Dec-2013 Final Revised: 17-Mar-2014

Accepted: 18-Mar-2014 Published: 28-Mar-2014

\section{References}

1. WHO. Measles. World Health Organization. 2013. I Website

2. WHO. Measles deaths decline, but elimination progress stalls in some regions. Improved vaccination rates critical for success Geneva: World Health Organization; 2013. | Website

3. CDC. Measles Overview. Centers for disease control and prevention. 2013. | Website

4. Tricou V, Pagonendji M, Manengu C, Mutombo J, Mabo RO and Gouandjika-Vasilache I. Measles outbreak in Northern Central African Republic 3 years after the last national immunization campaign. $B M C$ Infect Dis. 2013; 13:103. | Article | PubMed Abstract | PubMed Full Text

5. BBC. Swansea measles epidemic: Man's death investigated. 2013. | Website

6. Choudary A. WHO reports $\mathbf{9 4}$ measles outbreaks across Pakistan in January [electronic]. Lahore, Pakistan: Jang Group; 2013. | Website

7. MRI. The Measles \& Rubella Initiative. 2013. | Website

8. WHO. Disease early warning system and response in Pakistan. World Health organization. 2013. I Website

9. WHO-UNICEF estimates of MCV coverage. 2013. I Website

10. Correspondent. Disease spreads: Three children die allegedly from measles in Thar Pakistan. 2013. I Website

11. Usman A. Disease control: 4 children die from measles, 17 new cases reported. Lahore, Pakistan. 2013. I Article

12. Riaz H. Public health failings behind Pakistan's measles surge. Lancet. 2013; 381:189. | Article | PubMed

13. WHO. Reported measles cases and incidence rates by WHO Member States. 2012. | Pdf

14. McLean H. Measles-United States, 2011. Morbidity and Mortality Weekly Report. 2012; 61:253-7. | Article

15. WHO. Weekly Epidemiological Bulletin: Disease early warning system and response in Pakistan. 2013; 4. | Article

16. WebDesk. Measles claim lives of $\mathbf{2 0}$ children in $\mathbf{1 9}$ days in Sindh: Health dept. Pakistan. 2013. | Website

17. Correspondent. Measles in the city: 'Vaccination cover in Punjab shamefully low'. Pakistan. 2013. I Website

18. Usman A. Fighting measles: Province-wide vaccination must wait four more weeks. 2013. | Website

19. Corruption Perceptions Index data. TransparencyInternational. 2013. | 
Khan et al. Epidemiology Reports 2014,

http://www.hoajonline.com/journals/pdf/2054-9911-2-1.pdf

Website

20. Nishtar S. Corruption in health systems. Lancet. 2010; 376:874. | Article I PubMed

21. Nishtar S. Choked pipes--reforming Pakistan's mixed health system. J Pak Med Assoc. 2010; 60:252-3. | Article | PubMed

22. Transparencyinternational. National Corruption Perception Survey. 2010. I Pdf

23. Heartfile. Pakistan's health sector: does corruption lurk? Pakistan: The Heartfile; Transparency International; Ministry of Health. 2007. I Pdf

24. UNICEF. Situation Analysis of Children and Women in Pakistan 2012. Pakistan: United Nations Children Fund's (UNICEF). 2012. I Pdf

25. Khan T and Qazi J. Hurdles to the global antipolio campaign in Pakistan: an outline of the current status and future prospects to achieve a polio free world. J Epidemiol Community Health. 2013; 67:696-702. | Article | PubMed

26. Duke T and Mgone CS. Measles: not just another viral exanthem. Lancet. 2003; 361:763-73. | Article | PubMed

27. Wasif S. Measles outbreak: The epidemic isn't near; it's already here. Pakistan. 2013.| Website

28. Nebehay S. Measles deaths fall but vaccine gaps threaten progress: WHO. Reuters. 2013. | Article

29. USAID. Impact of infrastructure on immunization coverage. 2012. | Pdf

30. Ahmed T. Child immunisation: International bodies reject EPI report. Karachi, Pakistan. 2013. | Website

31. Babbar Y. Reasons behind deaths caused by measles outbreak Pakistan. 2013. | Website

32. Correspondent. Measles outbreak in Sindh: More than $\mathbf{3 0}$ children died in $\mathbf{2 0}$ days. Pakistan. 2012. | Website

33. Hasan Q, Bosan AH and Bile KM. A review of EPI progress in Pakistan towards achieving coverage targets: present situation and the way forward. East Mediterr Health J. 2010; 16 Suppl:S31-8. | PubMed

34. Naeem M, Khan M, Adil M, Abbas SH, Khan A and Khan MU et al. Coverage and causes of non immunization days for Polio; a consumer and procider perspective study in Peshawer. Journal of Pakistan Medical Association. 2011; 26:48-54. | Article

35. Cropp J and Ajaib R. Last year's floods in Sindh province continue to put pressure on food stocks. 2012. | Article

36. Kirsch TD, Wadhwani C, Sauer L, Doocy S and Catlett C. Impact of the 2010 pakistan floods on rural and urban populations at six months. PLoS Curr. 2012; 4:e4fdfb212d2432. | Article | PubMed Abstract | PubMed Full Text

37. Pakresponse. National Nutrition Survey Pakistan Pakistan. Aga Khan University; 2011.

38. Qazi MS and Ali M. Pakistan's health management information system: health managers' perspectives. J Pak Med Assoc. 2009; 59:10-4. | Article I PubMed

39. Cohen AL, Salam A, Bosan A, Perry R, lqbal S, Qureshi SN, Cairns L, Mach $\mathrm{O}$, Mahoney $\mathrm{F}$ and Hafiz R. Etiology of a suspected measles outbreak: preceding measles reduction activities in Pakistan. I Coll Physicians Surg Pak. 2009; 19:591-4. | Pdf | PubMed

40. Warraich $\mathrm{H}$, Zaidi AK and Patel K. Floods in Pakistan: a public health crisis. Bull World Health Organ. 2011; 89:236-7. | Article | PubMed Abstract | PubMed Full Text

41. CDC. Measles-United States, 2011. Morbidity and Mortality Weekly Report. 2012. | Article

\section{Citation:}

Khan T and Qazi J. Measles outbreaks in pakistan: causes of the tragedy and future implications.

Epidemiol Rep. 2014; 2:1.

http://dx.doi.org/10.7243/2054-9911-2-1 